\title{
Positive-Tone EUV Resists: Complexes of Platinum and Palladium
}

\author{
Miriam Sortland, ${ }^{1}$ Ryan Del Re,${ }^{1}$ James Passarelli, ${ }^{1}$ Jodi Hotalen, ${ }^{1}$ Michaela Vockenhuber, ${ }^{3}$ \\ Yasin Ekinci, ${ }^{3}$ Mark Neisser, ${ }^{4}$ Daniel A. Freedman, ${ }^{2}$ and Robert L. Brainard ${ }^{1}$ \\ 1. College of Nanoscale Science and Engineering, Albany, NY 12203 \\ 2. State University of New York at New Paltz, New Paltz, NY 12561 \\ 3. Paul Scherrer Institut, Villigen, Switzerland \\ 4. Sematech, Albany NY 12203
}

\begin{abstract}
The EUV photoreactivity of platinum and palladium mononuclear complexes has been investigated. Many platinum and palladium complexes show little or no EUV sensitivity, however, we have found that metal carbonates and metal oxalates $\left(\mathrm{L}_{2} \mathrm{M}\left(\mathrm{CO}_{3}\right)\right.$ and $\mathrm{L}_{2} \mathrm{M}\left(\mathrm{C}_{2} \mathrm{O}_{4}\right) ; \mathrm{M}=\mathrm{Pt}$ or Pd) are sensitive to EUV. The metal-carbonates give negative tone behavior. The most interesting result is that the metal oxalates give the first positive-tone EUV resists based on mono-nuclear organometallic compounds. In particular, (dppm) $\mathrm{Pd}\left(\mathrm{C}_{2} \mathrm{O}_{4}\right)\left(\mathrm{dppm}=1\right.$,1-Bis(diphenylphosphino)methane) (25) prints 30-nm dense lines with $\mathrm{E}_{\text {size }}$ of $50 \mathrm{~mJ} / \mathrm{cm}^{2}$. To improve the lithographic performance of (25), the processing conditions were studied. A bake study showed that bake affected sensitivity and dark loss very little, while dark loss worsened with development time. Derivatives of (25) were synthesized to explore the effect of molecular weight on resist sensitivity, but the study showed no correlation between molecular weight and sensitivity.
\end{abstract}

Keywords: Platinum, palladium, oxalate, photoresist, EUV, positive-tone.

\section{INTRODUCTION}

EUVL (Extreme Ultraviolet Lithography) is anticipated to succeed $193 \mathrm{~nm}$ immersion lithography to meet the demands of the $10 \mathrm{~nm}$ node. ${ }^{1}$ Unfortunately EUVL is facing major challenges that have, and still are, preventing this lithography from being implemented in manufacturing. One of the main challenges of EUVL is low source power. Highly sensitive resist systems are therefore essential to EUVL, which can supplement the source power to produce the required 100 wafers per hour. As EUV resists achieve better resolution, they must be coated thinner to prevent line collapse, ${ }^{2}$ which minimizes the resist absorption. Chemically Amplified Resist systems (CAR) are too transparent to EUV as they mainly consist of low EUV optically dense carbon, hydrogen and oxygen (Figure 1).

The low number of EUV photons available and the low EUV absorbance of the CAR resists leads not only to low sensitivity platforms but also to statistical roughness (shot noise) that limits LER. As industry is moving towards the 16 and $10 \mathrm{~nm}$ node, more sensitive resist systems are required. Inspired by the work of Inpria and Cornell University who were the first to introduce the concept of metal containing resists, ${ }^{3-6}$ we are introducing a resist platform consisting of high optical density molecular organometallic compounds. As the elemental composition of the resist determines the photon absorption at EUV, ${ }^{1}$ we propose that composing resists of high optical density metals will increase EUV photon absorption, thus answering some of the challenges facing EUVL.

Extreme Ultraviolet (EUV) Lithography VI, edited by Obert R. Wood II, Eric M. Panning,

Proc. of SPIE Vol. 9422, 942227 - @ 2015 SPIE · CCC code: 0277-786X/15/\$18

doi: $10.1117 / 12.2086598$

Proc. of SPIE Vol. $9422942227-1$ 
Figure 1 shows the periodic table with shading to symbolize the EUV optical density of the elements. In exploring the periodic table, we discovered successful resist systems based on a wide variety of elements. Here we will present the synthesis and lithographic evaluation of compounds containing platinum or palladium. Platinum and palladium behave very similarly, although palladium is more reactive. ${ }^{7}$ The resist systems have been evaluated lithographically at the Berkeley Micro Exposure Tool (BMET) and at the Paul Scherrer Institut (PSI) in Villigen, Switzerland.

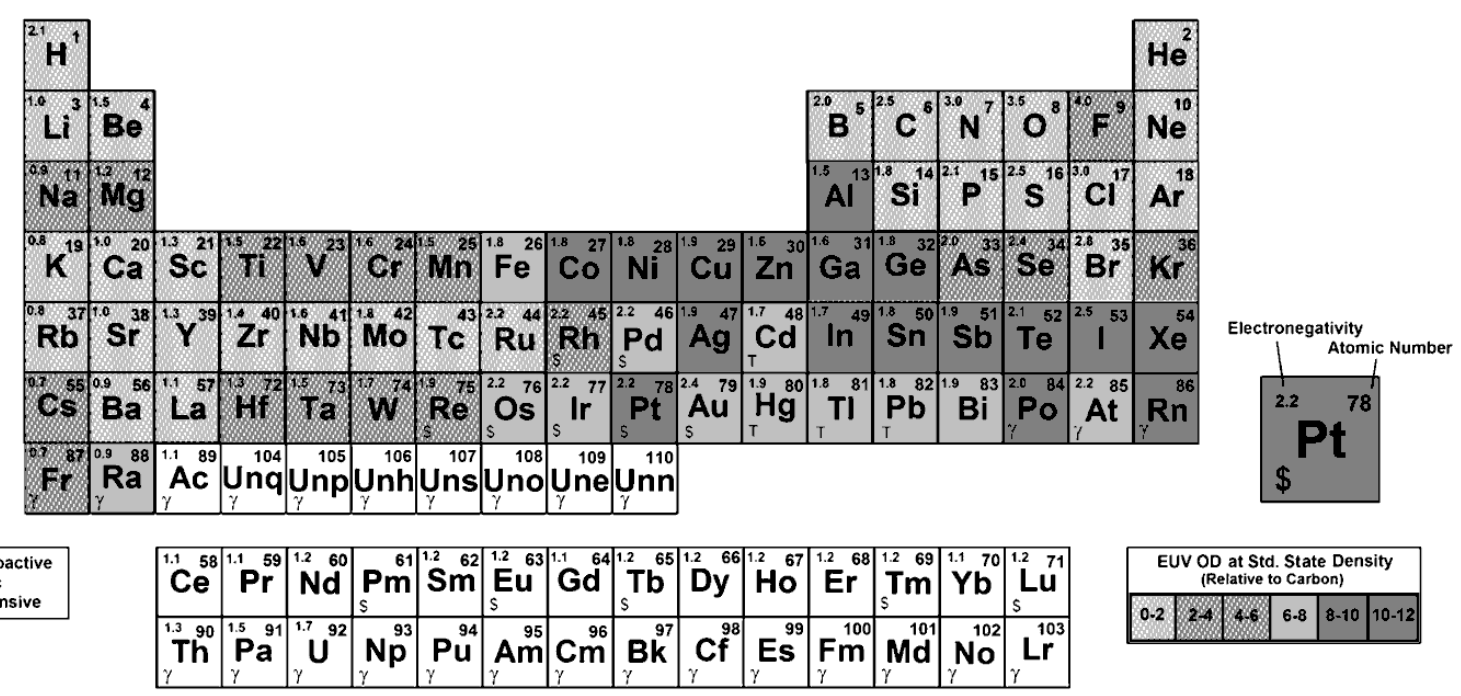

Figure 1. The periodic table with respect to optical density.

\section{RESULTS AND DISCUSSION}

\subsection{Preliminary Studies}

Previously, we have been successful in identifying organometallic complexes as having EUV sensitivity despite the fact that these complexes have never been shown to be photosensitive at longer wavelengths. ${ }^{8}$ Specifically, we have shown that tin oxoclusters undergo reaction upon exposure to EUV light by mechanisms most likely involving the homolytic cleavage of tin-carbon bonds. Based on this knowledge we preliminary tested the EUV lithographic performance of platinum and palladium by screening a wide range of synthetically accessible complexes (Figure 2), without being concerned with evidence of photoreactivity at longer wavelengths. These complexes are readily soluble, easy to spin coat and have high metal content. The complexes containing the ligand cis, cis-1,5-cyclooctadiene (COD) were suspected to $\beta$-hydride eliminate, which could create a photo-response in the resist upon exposure. The compounds were spin coated in either acetone nitrile/PMA or toluene and tested for lithographic performance at BMET. Unfortunately, no latent image was visibly detected but a chemical change did happen in the material upon exposure which could be seen when breathing on the material. We suspect that a polarity change happened in the material upon exposure to EUV giving it breath observability. Unfortunately, this change was not enough to produce an imageable resist. 


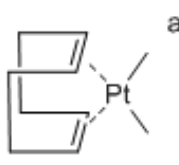

1

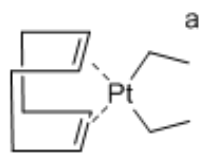

2

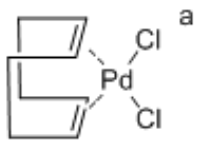

6

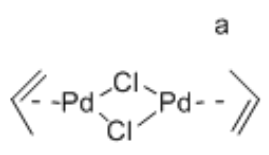

9

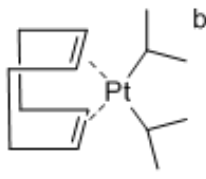

3
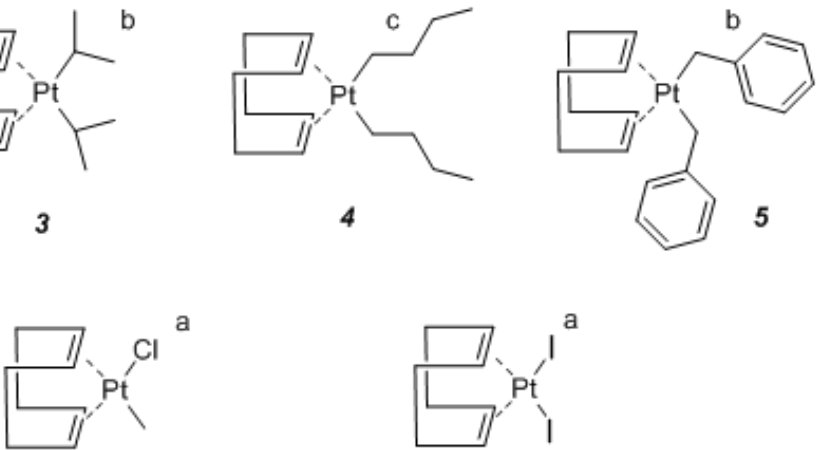

7

8

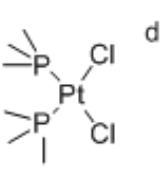

10

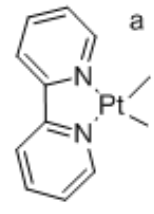

11

Figure 2. Preliminary investigation of EUV reactivity of platinum and palladium. Results: a) Latent image breath observable and image not visible. b) Faint latent image but image not visible. c) Latent image breath observable and image partly visible. d) Breath observable latent image and image.

\subsection{Platinum and Palladium Complexes with Azide, Carbonate and Oxalate}

After determining that the easily prepared platinum and palladium complexes described above gave poor EUV sensitivity, we began an investigation into platinum and palladium complexes in combination with ligands known for photoreactivity in transition metal complexes at longer wavelengths. We prepared complexes containing azide $\left(\mathrm{N}_{3}\right)$, carbonate $\left(\mathrm{CO}_{3}\right)$ and oxalate $\left(\mathrm{C}_{2} \mathrm{O}_{4}\right)$ ligands which are known to produce photoreactions at longer wavelengths for a number of transition metal complexes. ${ }^{9-12}$

\subsubsection{Azides}

We synthesized six azide complexes using both phosphines and amines as neutral ligands (Figure 3). ${ }^{11,13,14}$ These compounds were spin-coated from mixtures of methanol and ethyl lactate to form amorphous films, then evaluated lithographically at EUV using the interference lithographic tool at PSI. Unfortunately, the azide complexes showed no lithographic performance. The latent image was barely visible and development produced no visible image.<smiles>CC[PH](N)(c1ccccc1)P(=N)(c1ccccc1)P(=N)(c1ccccc1)c1ccccc1</smiles>

12

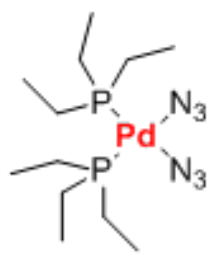

13

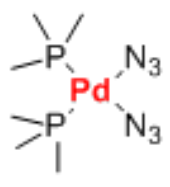

14<smiles>N[Pb](N)(N)NCc1ccccc1</smiles>

15

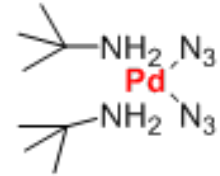

16

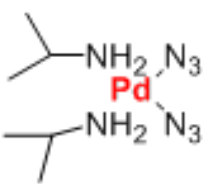

17

Figure 3. $\mathrm{L}_{2} \mathrm{Pd}\left(\mathrm{N}_{3}\right)_{2}$ complexes, where $\mathrm{L}=$ phosphines or amines. 


\subsubsection{Carbonates}

Four $\mathrm{L}_{2} \mathrm{M}\left(\mathrm{CO}_{3}\right)$ complexes were synthesized ${ }^{11}$ since transition metal carbonates are known to show photoreactivity to ultraviolet light (Figure 4). ${ }^{11,12}$ Indeed, we found that three of these resists exhibited negative-tone behavior as EUV resists. Unfortunately, their sensitivity was poor and they have poor solubility properties, and very little additional work was done with them.

\subsubsection{Oxalates}

The photochemistry of oxalates is well documented, ${ }^{10,11}$ and in our own work, we have found that oxalate complexes of first-row transition metals produce negative-tone EUV resists capable of 18-nm resolution with sizing doses of $30 \mathrm{~mJ} / \mathrm{cm}^{2}{ }^{2}{ }^{15}$ To investigate the EUV photo-reactivity of $\mathrm{L}_{2} \mathrm{M}\left(\mathrm{C}_{2} \mathrm{O}_{4}\right)$, four complexes were initially synthesized according to previously described methods (Figure 4). ${ }^{11}$ These compounds were spin-coated in either 1:2 acetone nitrile/ethyl lactate or 1:2 methylene chloride/PMA and exposed to EUV at PSI. Within the MORE project, $~ 90 \%$ of our resists have been negative tone. Consequently we were expecting the $\mathrm{L}_{2} \mathrm{M}\left(\mathrm{C}_{2} \mathrm{O}_{4}\right)$ to behave as negative tone resists and developed them accordingly. It was by a mere accident that we discovered the positive tone behavior of these resists by developing them in a mixture of methyl isobutyl ketone (MIBK) and toluene, not clearing the unexposed areas, but clearing the areas exposed (Figure 5). As seen in Figure 4, $(\mathrm{dppm}) \mathrm{Pd}\left(\mathrm{C}_{2} \mathrm{O}_{4}\right)(25)$ demonstrated the best sensitivity with an $\mathrm{E}_{0}$ of $78 \mathrm{~mJ} / \mathrm{cm}^{2}$ and was able to print $30 \mathrm{~nm}$ dense lines at an $\mathrm{E}_{\text {size }}$ of 50 $\mathrm{mJ} / \mathrm{cm}^{2}$ (Figure 6C).

\subsubsection{Processing Conditions of (dppm)Pd $\left(\mathrm{C}_{2} \mathrm{O}_{4}\right)(25)$}

A study was conducted to determine the effect of bake and development time on the shape of positive-tone contrast curves of (dppm) $\operatorname{Pd}\left(\mathrm{C}_{2} \mathrm{O}_{4}\right)$ (25). Specifically, we studied contrast curve performance with and without soft-bake; with and without post-exposure bake (PEB); and using short (10 s) and long (20 s) development times (Figure 7). The composition of the developer (10\% MIBK/toluene) was kept constant throughout the whole experiment. We studied two responses: $\mathrm{E}_{\mathrm{M}}$ and dark loss. As the contrast curves for the $\mathrm{L}_{2} \mathrm{M}\left(\mathrm{C}_{2} \mathrm{O}_{4}\right)$ resists behaves differently than conventional resists, we felt the need to define a point for equal comparison of sensitivity between the different experiments. $\mathrm{E}_{\mathrm{M}}$ is defined as the minimum dose at extrapolated contrast curve (Figure 7A). The $\mathrm{L}_{2} \mathrm{M}\left(\mathrm{C}_{2} \mathrm{O}_{4}\right)$ resist system struggles with dark loss, which is the loss in mass in the unexposed areas before and after development. Consequently we wanted to monitor dark loss and find the best processing condition, optimizing both sensitivity and dark loss.

For the most part, the lithographic performance of this resist was unaffected by bake. Although a couple of responses changed by $14 \%$, most changes were less than $5 \%$. Conversely, $\mathrm{E}_{\mathrm{M}}$ and dark loss were strongly dependent upon development time. This study indicates poor developer selectivity for this resist system. 


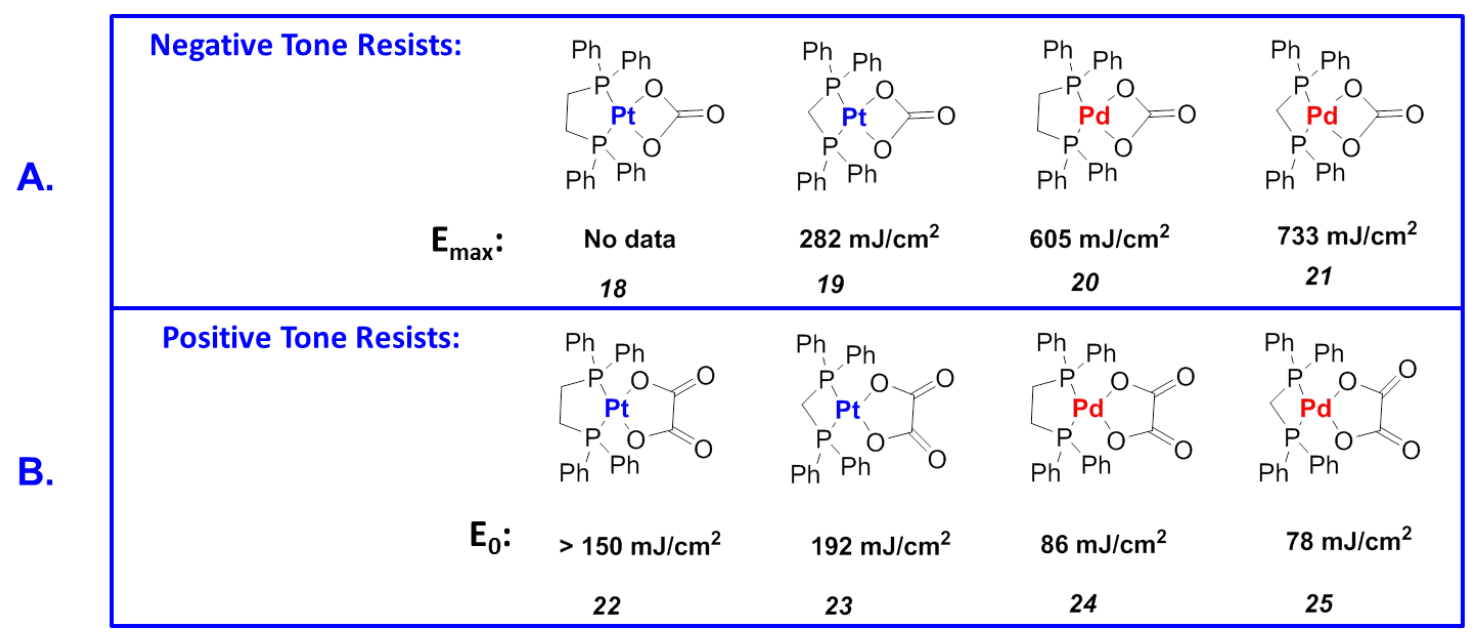

Figure 4. $\mathrm{L}_{2} \mathrm{M}\left(\mathrm{C}_{2} \mathrm{O}_{4}\right)$ and $\mathrm{L}_{2} \mathrm{M}\left(\mathrm{CO}_{3}\right)$ evaluated for EUV sensitivity. A) Platinum and palladium carbonates showing negative tone behavior. B) Platinum and palladium oxalates showing positive tone.
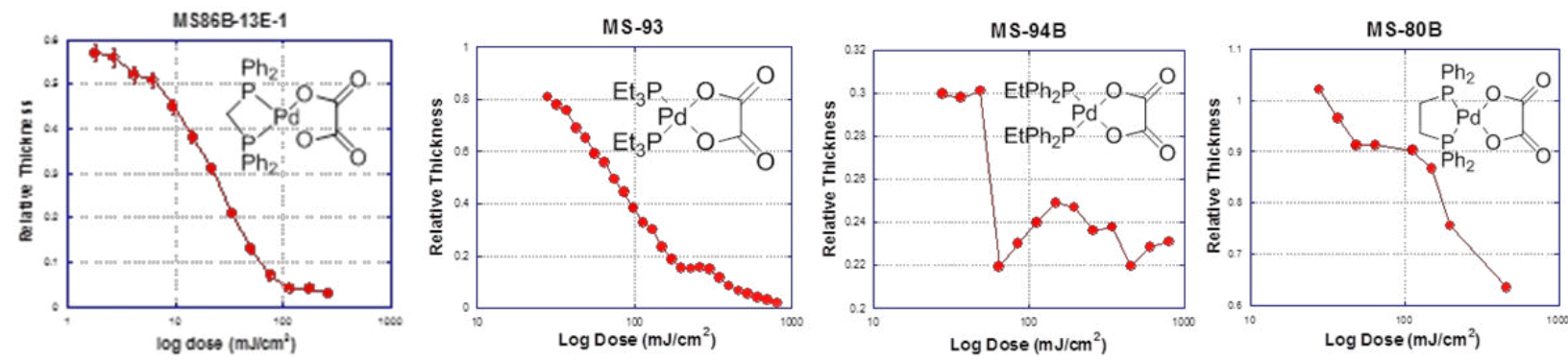

Figure 5. Contrast curves of selected palladium oxalate resists, all showing a positive-tone photo response.

\subsubsection{Effect of Metal and Phosphine Ligands}

Seven different platinum and palladium oxalates were synthesized with different phosphine ligands (Figure 8). ${ }^{11}$ These complexes were coated on wafers and exposed to EUV using the interference lithographic tool at PSI. In general, palladium complexes produced faster EUV resists than did platinum complexes. Direct comparisons can be made for complexes $\mathbf{2 3} v s .25$ and for $\mathbf{2 6} v s .27$. 

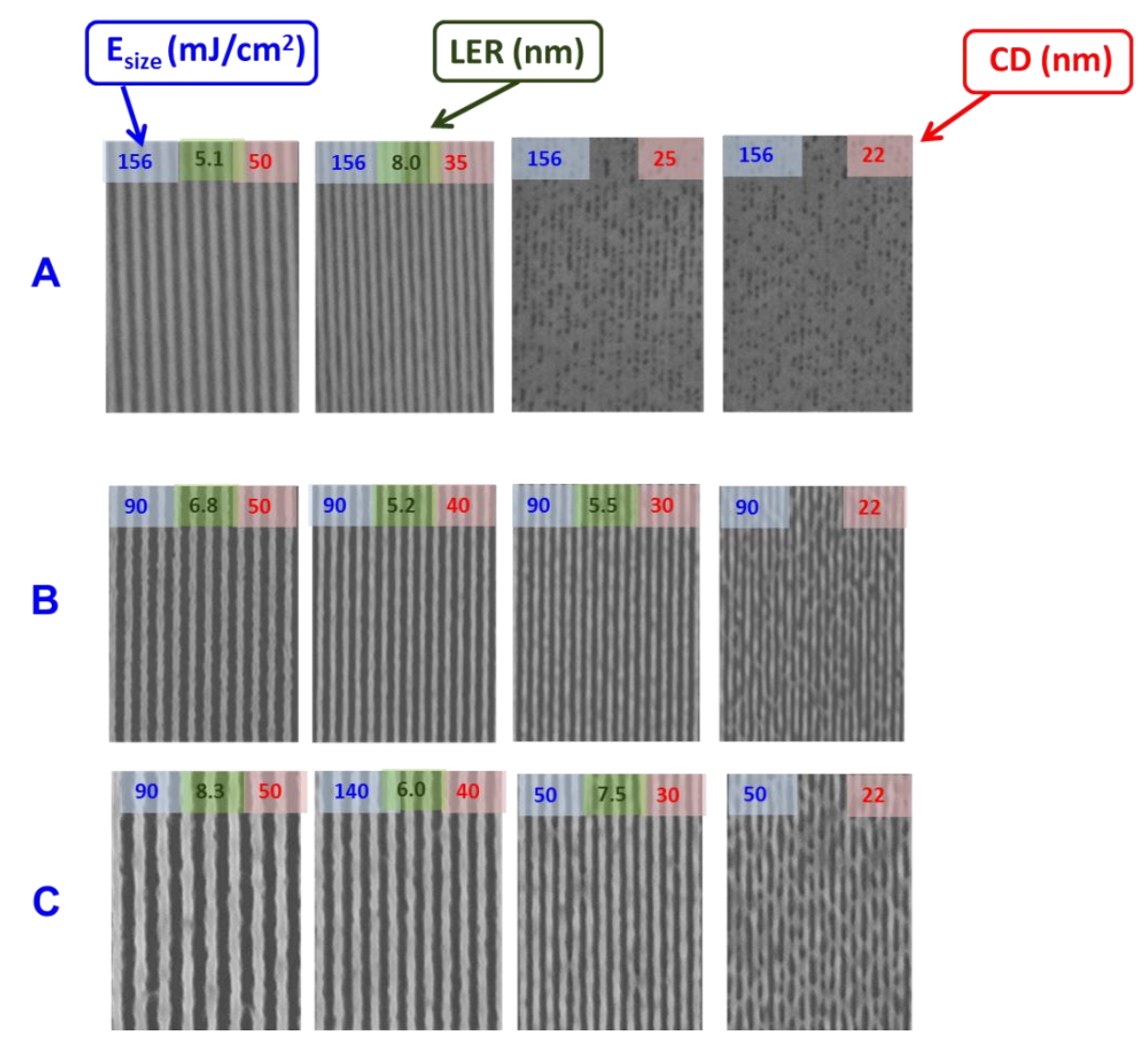

Figure 6. First positive-tone MORE photoresist: (dppm) $\mathrm{Pd}\left(\mathrm{C}_{2} \mathrm{O}_{4}\right)(25)$ gives resolution down to $30 \mathrm{~nm}$ and modulations down to 22nm. a) Developer: 10\% MIBK/Toluene, on underlayer b) Developer: $10 \%$ MIBK/Toluene, no underlayer c) Developer: 20\% MIBK/Toluene, no underlayer.

A.

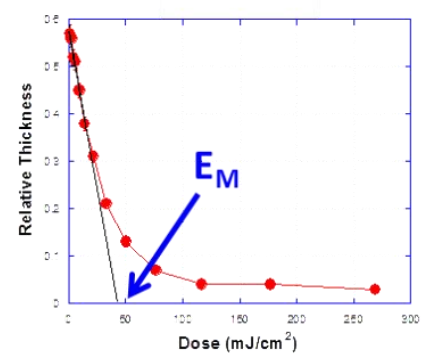

B.
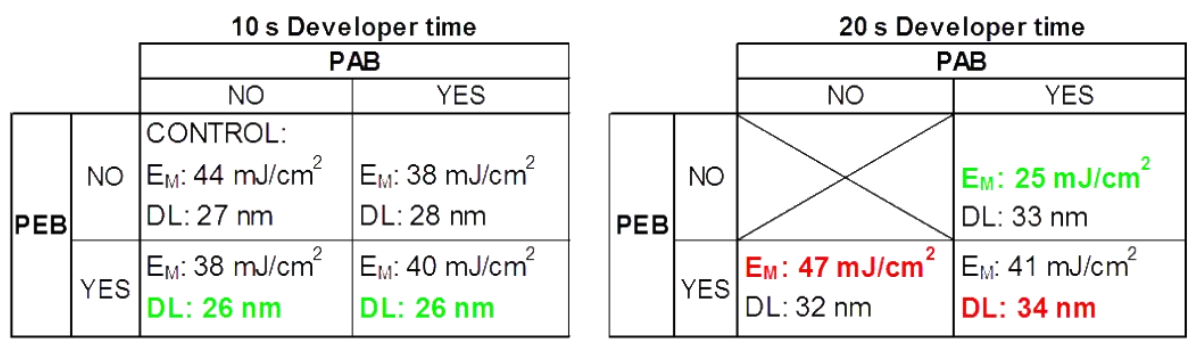

Figure 7. Bake study of (dppm) $\mathrm{Pd}\left(\mathrm{C}_{2} \mathrm{O}_{4}\right)(25)$. A) Contrast curve for (dppm) $\mathrm{Pd}\left(\mathrm{C}_{2} \mathrm{O}_{4}\right)$ showing $\mathrm{E}_{\mathrm{M}}$ as minimum dose at extrapolated contrast curve. B) Bake study, where dark loss (DL) and $\mathrm{E}_{\mathrm{M}}$ is compared. PAB/PEB: $90^{\circ} \mathrm{C} / 60 \mathrm{~s}$. 


\subsubsection{Proposed Photomechanism}

Potential photo-mechanisms and photoproducts are illustrated in Figure 9. Apart from the first step in the mechanism, which is well understood, the rest are hypothesized until future experiments can verify them. We hope to accomplish this through irradiation studies using NMR, IR and XPS as well as synthesizing authentic samples of potential photoproducts for comparison.

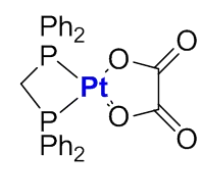

23

$192 \mathrm{~mJ} / \mathrm{cm}^{2}$

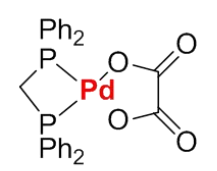

25

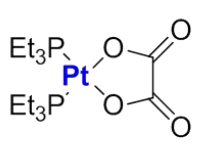

26

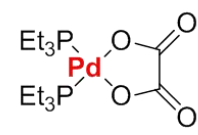

27

$122 \mathrm{~mJ} / \mathrm{cm}^{2} \quad 86 \mathrm{~mJ} / \mathrm{cm}^{2}$<smiles>O=C1O[Pb](Pc2ccccc2)OC1=O</smiles>

24<smiles>C[PH2+]P[PH]1(P)OC(=O)C(=O)O1</smiles>

28<smiles>O=C1O[Te](C(F)(F)F)(P(F)(F)(F)F)OC1=O</smiles>

29

$86 \mathrm{~mJ} / \mathrm{cm}^{2}$

$188 \mathrm{~mJ} / \mathrm{cm}^{2}$

$78 \mathrm{~mJ} / \mathrm{cm}^{2}$

Figure 8. $\mathrm{E}_{0}$ for different platinum and palladium phosphine oxalates.

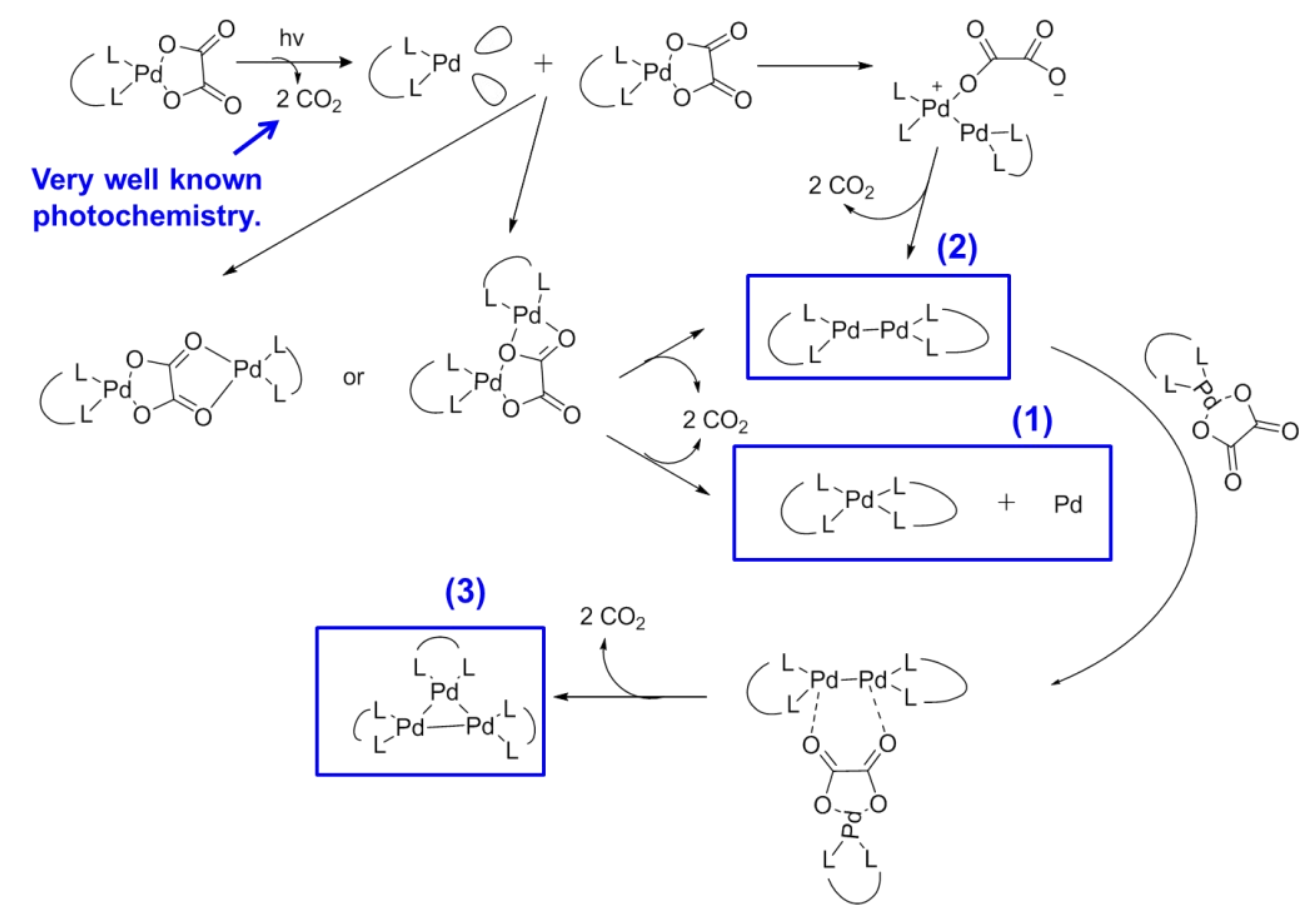

Figure 9. Proposed photo-mechanisms and photoproducts upon irradiation of $\mathrm{L}_{2} \mathrm{Pd}\left(\mathrm{C}_{2} \mathrm{O}_{4}\right)$ to EUV. 


\section{CONCLUSIONS}

We have investigated the photo-reactivity of mononuclear platinum and palladium complexes in EUV. Preliminary results showed the need for a photoactive ligand and lithographic performance was discovered for $\mathrm{L}_{2} \mathrm{M}\left(\mathrm{CO}_{3}\right)$ and $\mathrm{L}_{2} \mathrm{M}\left(\mathrm{C}_{2} \mathrm{O}_{4}\right)$ resist systems. The processing conditions were investigated for our most promising resist (dppm) $\mathrm{Pd}\left(\mathrm{C}_{2} \mathrm{O}_{4}\right)$ (25) which showed that bake had little effect on resist performance, but dark loss worsened with development time. Further investigation will be done to try to identify a better development solvent with less dark loss. A series of $\mathrm{L}_{2} \mathrm{M}\left(\mathrm{C}_{2} \mathrm{O}_{4}\right)$ complexes were synthesized to investigate sensitivity with respect to molecular weight and to better understand the photomechanism. We used $\mathrm{E}_{0}\left(\mathrm{~mJ} / \mathrm{cm}^{2}\right)$ to compare the resist performance, and we demonstrated that using palladium as a core metal offers faster resists than when platinum is used. The $\mathrm{L}_{2} \mathrm{M}\left(\mathrm{C}_{2} \mathrm{O}_{4}\right)$ resist system shows no correlation between sensitivity and molecular weight. Future work consists of isolating the photoproducts and mapping out the photo-mechanism of (25). By achieving this we hope to better understand how this resist system works and potentially help us to improve its lithographic performance.

\section{EXPERIMENTAL METHODS}

General. All reactions were carried out under inert atmosphere. Platinum metal was purchased from Alfa Aesar and palladium(II) chloride were purchased from Sigma Aldrich. cis, cis-1,5-Cycloocadiene was purchased from Sigma Aldrich and the phosphine ligands were purchased from both Strem and Sigma Aldrich. All other reagents were purchased from Sigma Aldrich. All reagents were used as received unless otherwise specified.

Resist Formulation and Imaging. Resist formulations were made by dissolving solids in 1:2 acetonitrile/ethyl lactate or 1:2 methylene chloride/PMA and filtering through a $0.2 \mu \mathrm{m}$ PTFE filter. Formulations were spin-coated on a custom underlayer (crosslinked hydroxyethyl methacrylate/methyl methacrylate copolymers) on 4-inch silicon wafers. 40-nm to $60-\mathrm{nm}$ thick resist films were made by adjusting spin-speed and formulation concentration. Resist films were then exposed with 13.5-nm radiation and developed with a mixture of MIBK and toluene or MIBK and hexanes. Exposures were performed at Paul Scherrer Institut on the XIL-II beamline using interference lithography.

SEM Metrology. Scanning electron microscope micrographs were collected at Paul Scherrer Institut on a Zeiss Supra VP55. Accelerating voltage was set between 1-2 KeV and the working distance was 4 mm. All images were at either $150 \mathrm{kx}$ or $200 \mathrm{kx}$ magnification.

LER Analysis. All LER values were obtained from the analysis of the SEM micrographs in SuMMIT Lithography Image Analysis software. 


\section{ACKNOWLEDGMENTS}

We would like to thank Sematech for financial support of this work. We would also like to thank DuPont for supplying us with ESCAP polymer and King Industries for supplying us with a thermal acid generator for organic underlayers. Finally, we would like to thank Patrick Naulleau at the Lawrence Berkeley National Laboratory for providing us with SuMMIT Lithography Image Analysis software.

\section{REFERNCES}

[1] Bakshi, Vivek "EUV Lithography" John Wiley \& Sons, Inc. 2009

[2] Brainard, R. L., et al., Journal of Photopolymer Science and Technology (2001) 14 (4), 531

[3] Y. Ekinci, M. Vockenhuber, M. Hojeij, L. Wang and N. Mojarad, Extreme Ultraviolet Lithography IV, Proceedings from SPIE, 2013, 8679, 867910.

[4] M. Trikeriotis, M. Krysak, Y. Chung, C. Ouyang, B. Cardineau, R. L. Brainard, C. Ober, E. Giannelis and K. Cho, Proceedings from SPIE, 2012, 8322.

[5] M. Trikeriotis, W. Bae, E. Schwartz, M. Krysak, N.Lafferty, P. Xie, B. Smith, P. Zimmerman, C. Ober and E. Giannelis, Proceedings from SPIE, 2010, 7639, 76390E-76390E-76310.

[6] W. Bae, M.Trikeriotis, J. Sha, E. Schwartz, R. Rodriguez, P. Zimmerman, E. Giannelis and C. Ober, Journal of Materials Chemistry, 2010, 20, 5186-5189.

[7] Hartley, The Chemistry of Platinum and Palladium

[8] "EUV resists based on tin-oxo clusters" B. Cardineau, R. Del Re, H. Al-Mashat, M. Marnell, M. Vockenhuber, Y. Ekinci, C. Sarma, M. Neisser, D. A. Freedman, R. L. Brainard Proceedings from SPIE 9051(2014)

[9] A. Vogler, C. Quett and H. Kunkely Ber. Bunsenges. Phys. Chem. 92 (1988) 1486-1492

[10] R.S Paonessa, A. L Prignano, W. C Trogler Organometallics 1985, 4, 647-657

[11] Anderson, G. K Journal of Organometallic Chemistry (1992) 434 (2), 253-259

[12] M. Henary, W.C Kaska, J.I Zink Inorg. Chem. (1989) 28, 2995-2997

[13] A. Tairai, P. K Bhattacharyya, R. Kar, P. Das Indian Journal of Chemistry (2012) 51A 1545-1552

[14] P. Muller, B. Schroder, J. A Parkinson, N. A Kratochwil. R. A Coxall, A. Parkin, S. Parsons and P. J Sadler Angew. Chem. Int. Ed. (2003) 42 No. 3

[15] "A molecular inorganic approach to EUV photoresists" Daniel Freedman, Miles Marnell, Brian Cardineau, Hashim AlMashat, Kara Heard, Amber Aslam, Ryan Del Re, Michaela Vockenhuber, Yasin Ekinci, Robert L. Brainard Conference 9051 Advances in Patterning Materials and Processes XXXI 9051-4 (2014) 